\section{UCDNN}

LIBRARY
University of Connecticut OpenCommons@UConn

Published Works

UConn Library

August 2004

\title{
Developing an Agriculture-Related Digital Project
}

Jonathan Nabe

University of Connecticut, jonathan.nabe@uconn.edu

Follow this and additional works at: https://opencommons.uconn.edu/libr_pubs

\section{Recommended Citation}

Nabe, Jonathan, "Developing an Agriculture-Related Digital Project" (2004). Published Works. 1.

https://opencommons.uconn.edu/libr_pubs/1 


\title{
Developing an Agriculture-Related Digital Project
}

\author{
Jonathan Nabe
}

\begin{abstract}
With the increasing expectation of information searchers for all information to be available online, digital projects are growing in number and importance. These projects allow libraries to become producers, if not of content, then of new accessibility options for their patrons. One librarian's experience in the development and coordination of a digital project in an academic setting is presented, in order to demonstrate potential best practices for similar projects. Selection, coordination, standards, outsourcing, and funding of projects are all discussed. It is possible relatively quickly and inexpensively to produce a useful, quality digital project.
\end{abstract}

KEYWORDS. digital projects, Connecticut Institute of Water Resources

\section{INTRODUCTION}

Digital projects are an increasingly important part of the academic library's landscape of resource offerings. They serve to enhance the library's visibility inside and outside the university community, create opportunities for faculty/staff cooperation, capitalize on new technology to expand access to information resources, and serve as a vehicle to develop new skills in the profession. ${ }^{1}$ Because of their high visibility, even small projects can produce significant favorable results in enhancing the status and perceived value of librarians among faculty and users inside and outside of the home institution. This, in itself, is some justification for the effort, time, and money that must be invested. In a time of tight budgets and cost-cutting initiatives throughout all levels of institutional funding, increased visibility and status will help any efforts to retain or enhance library personnel and funding.

Almost anything ever created in any format has the potential to be a digital project. Every library in the country has possible projects ready for the doing. The most important step in designing a project or a collection of projects is deciding what is 
worthwhile and what realistically is possible. To quote the Curator for Preservation in the New York University Libraries, "To select and select well is critical to the success of the digital library."2

\section{THE CTIWR PROJECT}

The project discussed below is the result of a partnership between the University of Connecticut Libraries and the Connecticut Institute of Water Resources (CTIWR). The CTIWR was created by the Water Resources Research Act authorized by P.L. 101397, which provides for Water Resources Research Institutes in each of the fifty states, the trust territories, and the District of Columbia. The CTIWR was founded in 1965 with the goals of organizing effective research on water resources in the state and cooperating with Connecticut colleges and universities in addressing regional and statewide water issues. One of the products of the CTIWR is a series of Special Reports, which represent water-related research conducted under the auspices of the Institute of Water Resources (IWR), dating from its inception to the current date. As a result of the partnership, the thirty-seven reports are currently available as PDF files, and more will be added as they are created by the IWR.

I became involved in this project in my capacity as the Agriculture and Natural Resources liaison for the University of Connecticut libraries. As such, it is my responsibility to interact with the designated faculty and staff members in the departments, to find out what they are doing and how the libraries may help them in their efforts. The apparent need for the digitization of the Special Reports was first revealed in the course of a discussion with the Associate Director of the IWR. Networking with individuals involved in the creation, management and distribution of locally produced 
research findings, reports, papers, etc. is often the simplest and most effective method for discovering the potential need for a digital project. These individuals will have insight into the use of material that falls under the radar of library collection management. ${ }^{3}$ In addition, partnering with entities such as the CTIWR provides an opportunity to share the burden of a digital project, financial and otherwise. In the course of my discussions with the Associate Director, it became clear that there was a substantial user base for these reports. At the time, the needs of these users were being met in an untimely and costly way. While the reports were listed on the IWR Web site, they were only available by requesting hard copies from the Institute office. Many of the documents had to be photocopied, since there were no longer enough remaining copies in print for general distribution. Some were in poor physical condition, and the Institute's collection was incomplete.

The project was thus demonstrably worthwhile, in terms of meeting an information need that had been largely unmet, and providing easy online access to a resource that was largely hidden to the world. In this case, what was proposed was scanning the reports (some 3,000 pages) and making them available online. This seemed simple and straightforward enough. As the project developed, value-added features were judged to be important: the ability to search, not just within the individual reports, but across them; the addition of metadata to aid in resource discovery beyond the library's catalog; and the potential to use the project as a pilot for scaling up, to create a regional database of reports and papers from all of the IWRs in the region. Each of these added features would increase the time and money necessary for the project, so that eventually, the project was broken into two phases: Phase I, to scan the reports and have searchable 
PDFs available online; and Phase II, which would involve all the additional effort to make the project valuable enough to other IWRs so that they would support a regional effort. What had been simple and straightforward — and reasonably cheap — was now a labor-intensive and more costly venture. This is not atypical of digital projects: what you see at first may be just the tip of the iceberg.

\section{INHOUSE OR OUTSOURCED?}

By breaking the project into two parts, it was possible to get the reports online in a reasonable time, without getting bogged down in a lot of technical details important for the larger goal, but less essential for the immediate task at hand. To accomplish this first phase, it was necessary to decide who would do the scanning. While the capability existed for doing this work both within the IWR and the libraries, after careful consideration of the quantity of pages to be done and the need for high standards for each page, the decision was made to outsource this part of the job. While doing the work inhouse would have allowed local control, it would have been less cost-efficient than outsourcing. The number of companies doing this type of work has increased, and the economy of scale that can be realized by choosing one of them is impossible to ignore.

The selection process can be time-consuming, however. While my project may have seemed simple at the outset, by the time we got around to soliciting vendors for the project, the list of project specifications was seven pages long. The technical details must be worked out beforehand, so that vendors know exactly what is required of them. These vendors require the information in order to draw up a cost estimate of the project. The cost estimates themselves are the predominant factor in selecting a vendor. Other factors include whether outsourcing overseas is deemed acceptable, as a number of vendors use 
offshore sites for the actual work; the amount of time needed to complete the project (timing was important for us, as we were pushing fiscal year end dates); the methods of handling the material, where the material may be the sole existing copy or is otherwise valuable (this was the case for my project, and the question of unbinding and scanning was an issue that had to be negotiated); the responsiveness and flexibility of the vendor, which can be measured in the course of communications before arranging a contract (communications are crucial—we had several rounds of talks with a couple of vendors, after narrowing our search); the vendor's acceptance of the responsibility for addressing any errors discovered by the project personnel upon completion of the project (easily overlooked, but a very important issue to state in the contract); and experience with similar projects. Once a vendor is selected, all terms need to be committed to writing, so that both parties have a clear understanding of the terms of the arrangement. Contracts are essential, and a uniform contract for the libraries for all such similar work can help prevent the omission of important issues.

\section{IDENTIFYING AND SELECTING PROJECTS}

Because of library budget constraints, some method of determining the appropriateness of projects from the huge pool of potential digitization efforts needs to be in place and followed. Since there is such a large pool of potential projects, a defined set of criteria help to establish justification for librarywide support—or lack of support—for any given project. At the University of Connecticut Libraries, this structure for selecting projects is embodied in a Digital Collections Facilitation Team (DCFT), composed of representatives from the library areas that may be impacted by the decision to support a digital project. ${ }^{4}$ Representatives from collection services and systems are crucial 
participants in this process. Collections services personnel may be involved in many ways; creating metadata and MARC records are the most important. In the IWR project, collections personnel performed original cataloging for many of the documents and created records for the library's catalog. Systems staff members were and are responsible for uploading the completed files onto a library server and maintaining that server as well. These simple examples illustrate the need for planning upfront and including involved colleagues in that planning. With workflows already overwhelming staff, any new entrant into that flow needs prior approval if it is to be carried safely through to the finish. Indeed, only with the input of these staff members can a realistic timetable be established.

There are other benefits to having an established team or task force or committee with responsibility for selecting and shepherding digital projects. At the University of Connecticut, since the recommendations of the Team are forwarded to the library administration and signed off on by the library director, the digital projects have the stamp of approval from the institution as a whole. This means that the library has recognized the project as a priority, and all staff members are expected to cooperate in whatever ways are appropriate to their positions, in order to complete the project. In short, it minimizes obstacles to getting something done.

The DCFT also requires a partnership agreement with any cooperating body outside the libraries: in my case, the IWR. This carefully lays out what the library is committed to do on the project and also specifies the responsibilities of the partner organization. Many projects will involve cooperation with some other body, and it can be vitally important to ensure that these partners commit (preferably in writing) to certain 
functions and support such as delivering documents, guaranteeing copyright, marketing, and perhaps financial support. Our partnership agreement also specifies the primary contact people for the libraries and the IWR.

Having a team such as the DCFT also allows the library to bring its expertise to bear on the selection and development of digital projects. DCFT members have all been involved in prior projects, and they raised questions about the IWR project that would not have occurred to the IWR project staff, until they had become urgent—perhaps too urgent to do much about. In particular, details of document standards, metadata, and archiving were all brought up by the Team and resolved with their help. Coordinating all the people involved was work enough, but if it had been necessary to micromanage all the details without the benefit of the DCFT, the finished project would have been much sloppier. Because of their past experience, the Team was also able to provide advice about outsourcing vendors, eliminating the need for duplicative research among leaders of all of the Libraries' digital projects. In these ways, a team like the DCFT can serve effectively as a knowledge base for all other library staff and significantly reduce the drag time in a multitude of activities that go with a digital project. The benefits are reciprocal. My project was the first text-only project for the University of Connecticut libraries, and the members of the team learned considerably from studying the various issues involved, so that they and the Libraries as a whole are better positioned to pursue similar efforts in the future.

\section{CONCLUSION}

Once begun, digital projects never really end. If nothing else, servers have to be maintained. In some cases, including this one, new documents will be created and must 
be added to the project. Marketing is also an ongoing process. The CTIWR Special Reports are located on a library server, but the primary entry point is the IWR Web site itself. The libraries also link to the reports from a central digital projects page. A column appeared in the libraries' newsletter, alerting the university community to the availability of the reports. Of course, the online availability is a method of marketing itself. A Google search on Connecticut water law retrieves one of the reports as the top listing in the results. This, of course, was the ultimate goal.

As mentioned, it is hoped that it will be possible to scale up this project to include all of the regional IWR reports. The first step will be for the CTIWR Associate Director to discuss the possibility with the other regional directors. Some states have their reports online, but none are searchable PDFs, and many of them suffer from having been done in-house, with little or no concern for standards. There is certainly room for adapting this project at the regional or even national level, which may be the case for many similar projects. This is another reason that, once begun, digital projects never really end.

It is not necessary to have a collection of extremely rare materials in order to produce a successful digital project. Creating new access to old resources, gaining institutional experience, and heightening library visibility may combine to provide sufficient justification for the effort involved in developing a digital project. For the University of Connecticut Libraries, the CTIWR, and the readers of the Special Reports, this project has been a win-win situation; for myself, it has been an educational and rewarding experience.

\section{NOTES}


1. For more on the benefits of digital projects, see Lim, Adriene. "Collaborative Digitization Projects: Opportunities to Enhance Teaching and Learning," Information Technology and Libraries v.22, no.2 (June 2003), p. 75-78.

2. De Stefano, Paula. "Selection for Digital Conversion in Academic Libraries," College \& Research Libraries v.62 no.1 (January 2001), p. 58-69.

3. Others have had similar experiences in becoming involved in agriculture-related digital projects; see Russell, Beth M. "From the Ground Up: Lessons Learned from a Librarian's Experience with Digitizing Special Collections," College \& Research Libraries News v.62, no.6 (June 2001), p. 603-6.

4. The charge of the University of Connecticut Digital Collections Facilitation Team can be found at http://digitalcollections.uconn.edu/about.html. 